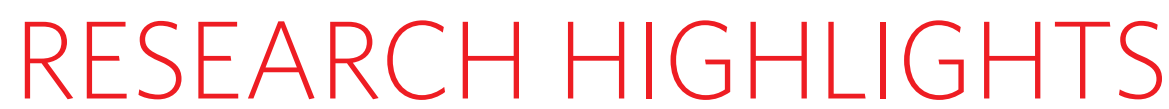

\title{
Not so hot spots
}

Earth Planet. Sci. Lett.

doi:10.1016/j.epsl.2005.10.012 (2005)

The volcanoes of Hawaii (pictured) may

give vent to the fury of the deep Earth, but

the plumes of magma that feed such hot

spots carry little of the core's heat, say

Eric Mittelstaedt at the University of

Hawaii and Paul Tackley at the Swiss

Federal Institute of Technology Zurich.

The researchers' computer simulations

of a single plume show that it transports

only $10-50 \%$ of the heat crossing the

boundary between the Earth's core and

IMAGE

the mantle in the region where the plume

rises. This has been observed in

simulations before, but the new work

makes more realistic assumptions about

the geophysical properties of the mantle,

such as the variation in its viscosity.

\section{PHOTONICS}

\section{Green light for white light}

Adv. Mat. 17, 2974-2978 (2005); Appl. Phys. Lett. 87, 231901(2005)

Getting light-emitting diodes (LEDs) to produce white light has always been difficult - such devices are mostly made by combining red, blue and green emitters. But now there are two ways to make white light from a single emissive ingredient.

Lixiang Wang and his colleagues of the Changchun Institute of Applied Chemistry in China grafted red- and green-emitting organic groups on to the blue-emitting main chain of an organic polymer to create a whitelight organic LED.

In a separate study, Koji Nishizuka of Kyoto University and his co-workers in Japan drew white light out of an inorganic semiconductor, indium gallium nitride, by varying the amount of indium through the device's crystalline film: the more indium,

IMAGE

UNAVAILABLE FOR COPYRIGHT REASONS the longer the emission wavelength. The resulting rainbow mixture of wavelengths combines to give a greenish white light.

\section{IMMUNOLOGY}

\section{Making mice tweak}

Cell 123, 931-944 (2005)

A protein known as TWEAK seems to act as a brake on innate immunity, say Avi Ashkenazi and his co-workers at the company Genentech in San Francisco, California.

Innate immunity is the body's first line of defence against infection. It also influences our later, adaptive immune response.

Ashkenazi's group bred mice deficient in the Tweak (or Tnfsf12) gene to investigate its role.

TWEAK-deficient mice died from overstimulation of their innate immune cells (pictured left) on exposure to a bacterial toxin. But these mice also made more of the proteins that can predispose cells to secrete pro-inflammatory signals, which can stimulate adapative immunity. The researchers suggest that manipulating TWEAK may help in treatments for infections and auto-immune diseases.

\section{CHEMISTRY \\ Double delivery}

J. Am. Chem. Soc. doi:10.1021/ja056841t (2005) Micelles are aggregates of molecules that form compartments, which can be useful for packaging and transporting smaller chemicals such as pharmaceuticals.

Pushing these structures to new limits, Timothy Lodge and his colleagues from the University of Minnesota in Minneapolis have created a micelle with two internal compartments, and have shown that a different type of molecule can be stored in each. This means that two chemicals that would otherwise react with each other could potentially be delivered to the same place at the same time.

The multicompartment micelle is made from a polymer that has three different arms. The polyethylethylene and polyperfluoropropylene oxide arms segregate within the micelle core to form the distinct storage areas. Polyethylene oxide pokes out of the sides, making the packages soluble in water.

\section{NEUROSCIENCE \\ Reflecting badly}

Nature Neurosci. doi:10.1038/nn1611 (2005) Brain cells that let us mirror the actions of others could hold the key to the social problems seen in autism, say researchers.

Mirella Dapretto and her team at the University of California, Los Angeles, studied mirror neurons in normal children and in those with mild autism. These neurons normally fire both when a person performs a particular action and when that person sees someone else performing the same action. They are thought to be key to our ability to automatically understand and empathize with the actions and emotions of others.

The team performed brain scans on both sets of children while they either imitated or just watched pictures of emotional facial expressions. The mirror neurons in the autistic children were far less active than normal, and were least active in the children whose social skills were worst affected. 


\section{GENETICS}

\section{Ripped genes}

Nature Genet. doi:10.1038/ng1695; 10.1038/ng1696; 10.1038/ng1697 (2005)

Our genomes are shot full of holes, according to three reports from researchers in the United States and Britain. Collectively, they have discovered 1,000 previously unknown gaps, or deletions, in the chromosomes of normal individuals.

The deletions, ranging from tens to hundreds of thousands of DNA base pairs, are smaller than have previously been found. The teams hope that the findings will shed light on how variations in our genomes affect our predisposition to disease.

The researchers made use of data already collected as part of the international HapMap project, which has catalogued variations at single bases in the genome, termed single nucleotide polymorphisms, or SNPs.

Deletions could be identified from apparent inconsistencies in the SNP data, and then tracked through their close association with neighbouring SNPs.

\section{IMMUNOLOGY}

\section{Breathe easy}

J. Exp. Med. 202, 1563-1573 (2005)

Treatment with a tiny piece of DNA before exposure to allergens can stop an asthmatic reaction by suppressing the immune system, researchers say.

Edith Hessel of Dynavax Technologies in Berkeley, California, and her colleagues showed that, in mice, the short immunostimulatory DNA molecules act by inhibiting $T$ helper type 2 cells, which normally launch a response against foreign particles entering the body. Immunologists

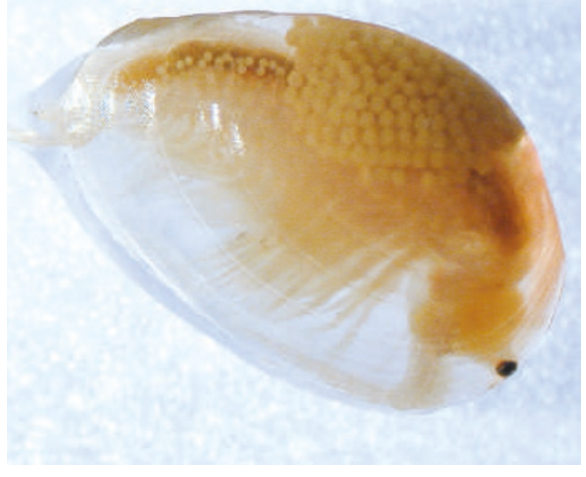

had previously thought that such treatments acted later, by neutralizing the proteins produced by $\mathrm{T}$ helper cells.

The DNA sequences apparently have a second means of blocking allergic airway inflammation: they prevent lung cells from presenting foreign particles to the $\mathrm{T}$ helper type 2 cells.

\section{POPULATION DYNAMICS \\ Deviant sexual practices}

Proc. R. Soc. B doi:10.1098/rspb.2005.3370 (2005) Almost all sexually reproducing species are either hermaphroditic, meaning that individuals have both male and female sex organs, or dioecious, with distinct males and females. But researchers have now found a group of freshwater shrimp species that feature both hermaphrodites and males.

This population make-up, known as androdioecy, is usually thought to occur only as a transition between hermaphroditism and dioecy. But Stephen Weeks of the University of Akron in Ohio and his colleagues, having studied more than 33,000 shrimp from 36 locations around the globe, report that this situation may have persisted stably in the genus Eulimnadia for as long as 180 million years.

Phylogenetic analysis of the genus, which features dozens of species (such as Eulimnadia texana, pictured left), suggests that androdioecy has survived several speciation events.

\section{MOLECULAR BIOLOGY}

\section{Strike while the ion is hot}

EMBO J. doi:10.1038/sj.emboj.7600893 (2005)

The mechanism by which pain receptors become more sensitive on stimulation is much debated. A team led by Peter McNaughton of the University of Cambridge, UK, is weighing into the controversy with a new mechanism for how nerve growth factor (NGF) may boost sensitivity to heat by promoting the opening of heat-activated ion channels.

McNaughton and his colleagues show that the binding of NGF to TrkA receptors in the nerve-cell membrane activates the enzyme known as Src tyrosine kinase. This enzyme phosphorylates the ion-channel protein TRPV1, which in turn triggers insertion of the ion channel into the cell surface membrane.

The findings suggest that researchers should revise the model pathway for the activation of TRPV1 channels, which was thought to involve breakdown of the membrane phospholipid PtdIns $(4,5) \mathrm{P}_{2}$, known as $\mathrm{PIP}_{2}$

\section{Correction}

In our Research Highlight 'Talking about regeneration' (Nature 438, 534; 2005), credit for the work should have been given to Alejandro

Sánchez Alvarado and his team at the University of Utah School of Medicine in Salt Lake City.

\section{JOURNAL CLUB}

\section{Peter Crane \\ The Royal Botanic Gardens, Kew, London, UK}

The director of Kew gardens charts the journey towards mapping the variety of plant life.

I often feel a slight twinge of envy and frustration when confronted with the elegant global analyses of species richness and distributions that are available for birds and mammals.

Such analyses can help to guide conservation planning. But the sheer number of plant species more than 20 times the number of birds and mammals combined make similar studies in my area a daunting prospect.

Increasingly, however, botanists are rising to the challenge. A recent paper from the Nees Institute for Plant Biodiversity at the University of Bonn, Germany, and WWF-US in Washington DC presents the best map available of global plant species richness (G. Kier et al. J. Biogeogr. 32, 1107-1116; 2005). This is a big step forwards - despite the fact that data for more than half the 867 ecoregions studied was poor, and fewer than a fifth had complete lists of the plant species present.

In reality, I'm pretty certain that knowledge of the distribution of plant species is not quite this bad, but uneven information and the difficulties of drawing it all together present formidable challenges.

What we really need, for science and for conservation, is a working list of all known plant species, linked to fine-grained information on their global distribution. Species lists are already available, or are close to completion, for several very large groups of plants, and also for some continents. And for distributions, a vast amount of data already exist, in partly synthesized form, in databases, herbaria and libraries around the world.

The effort required to collate this data is significant, but it is not beyond our reach. Given the pace of change in our environment we should do the job now, while it can still be useful. 